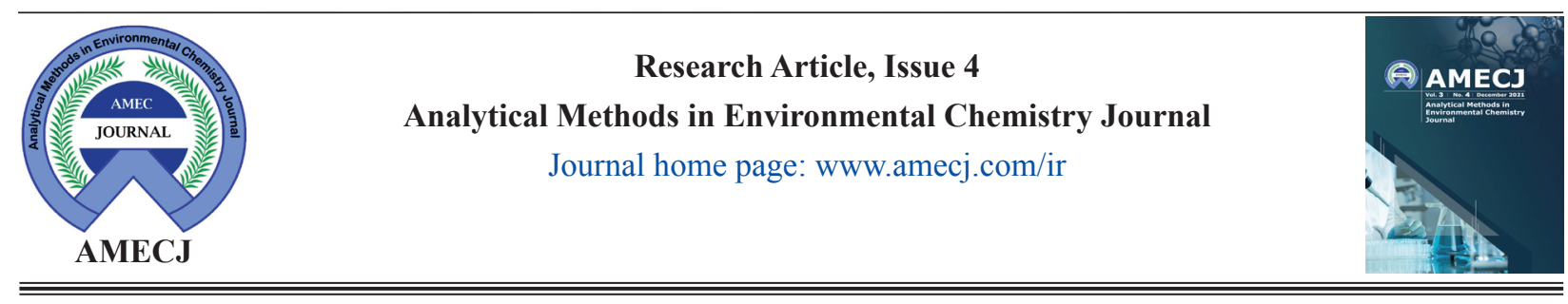

\title{
Removal of benzene vapor from the air based on novel tantalum metal-organic framework (Ta-MOF) adsorbent by gas flow solid-phase interaction before determination by gas chromatography
}

\author{
Mohammad Bagher Aghebat Bekheir ${ }^{\text {, Mohammad Reza Rezaei Kahkha }}{ }^{\mathrm{b}}$, Nasser Hasheminejad ${ }^{\mathrm{a}}$ \\ and Ali Faghihi-Zarandi ${ }^{a, *}$ \\ ${ }^{a}$ Department of Occupational Health and Safety at Work, Kerman University of Medical Sciences, Kerman, Iran \\ ${ }^{b}$ Department of Environmental Health Engineering, Faculty of Health, Zabol University of Medical Sciences, Zabol, Iran
}

\section{A R T I C L E I N F O :}

Received 12 Aug 2021

Revised form 15 Oct 2021

Accepted 17 Nov 2021

Available online 29 Dec 2021

Keywords:

Adsorption,

Gas flow solid-phase interaction,

Tantalum metal-organic framework, Gas chromatography

\begin{abstract}
A B S T R A C T
Benzene has a carcinogenic effect on the human body and adsorption from the air is the best way to control it. By this research, benzene vapor was removed from the air based on a tantalum metal-organic framework (Ta-MOF) by gas flow solid-phase interaction (GF-SPI). Benzene adsorption with Ta-MOF was studied in the static and dynamic systems at room temperature. The benzene concentration was analyzed by gas chromatography equipped with an FID detector (GC-FID). The factors affecting benzene removal efficiency like initial concentration of benzene, amount of adsorbent, exposure time, flow rate, and temperature were studied and optimized. The results showed us, the adsorption capacities range of Ta-MOF for benzene in the static and dynamic system were obtained between 90-160 mg $\mathrm{g}^{-1}$ and $65-135 \mathrm{mg} \mathrm{g}^{-1}$, respectively. Also, the high removal efficiency was achieved by more than $95 \%$ at $45^{\circ} \mathrm{C}, 67.5 \mathrm{mg} \mathrm{L}^{-1}$ benzene concentration, $0.5 \mathrm{~g}$ of Ta-MOF, and the flow rate of $250 \mathrm{~mL} \mathrm{~min}{ }^{-1}$ for a dynamic system. By dynamic system, the benzene is generated in the chamber, stored in a bag, and then moved on the surface of Ta-MOF. The GF-SPI method was validated by GC-MS and spiking real samples.
\end{abstract}

\section{Introduction}

Volatile organic compounds (VOCs) contain a carbon structure with a high vapur pressure at room temperatures [1]. These compounds are known air pollutants released through industrial activities such as liquid fuels and cleaning supplies [2]. Benzene is a hazardous pollutant in the air that workers in various industries (oil and chemicals) exposure to it [3]. Benzene has been classified as a

\footnotetext{
*Corresponding Author: Ali Faghihi-Zarandi

Email: Alifaghihi60@yahoo.com

https://doi.org/10.24200/amecj.v4.i04.155
}

definitive carcinogen in humans since 1979 based on sufficient evidence of leukemia. Benzene can replace by toluene or derivatives with less toxicity $[4,5]$. Benzene exists in fuels such as gasoline and is used in the production of styrene, dyes, inks and polymer products $[6,7]$. Benzene enters into the air through different ways such as gasoline leakage, pipelines and petrochemical effluents[8]. Exposure to benzene can affect human health and cause cancer, CNS impairment, and kidney diseases [7, $9,10]$. The benzene is volatilized and distributed in air, soil, water and foods [11,12]. Exposure to BTEX products causes many problems in the 
human body [13-15]. By increasing stringent environmental standards, the actual control for the removal of VOCs is the principal aim [16]. Methods developed to control and remove VOCs emission on industrial plants including, condensation, adsorption, catalytic oxidation, and biodegradation methods. Whereas adsorption onto sorbents such as activated carbon, zeolites, and cotton fibres has been the reliable option so far $[17,18]$. Adsorption is one of the most efficient ways to control the emission of VOCs [19]. Some common adsorbents for the adsorption process are carbon quantum dots(CQDs), graphene(NG), resin, zeolite, and carbon nanotubes [20]. Metal-organic frameworks (MOFs) are relatively new compounds made of porous crystal materials and are being studied as adsorbents since 1998 [21]. These materials are regular polymers that are formed from different metals and bonds between metals created by organic compounds [22]. Organicmetal framework compounds use in clean energy, as the most important storage devices for gases such as hydrogen and methane, as well as highcapacity adsorbents to meet various separation needs23] ]. The previous studies have shown that these adsorbents have excellent performance in absorbing benzene vapours. For instance, in 2008, Bright and colleagues studied benzene adsorption efficiency on various adsorbents made from MOFs. The adsorption occurs at the same conditions at $25^{\circ} \mathrm{C}$ and $440 \mathrm{ppm}$ benzene concentration. Also, the adsorption capacities of the adsorbents varied from 2 to $176 \mathrm{mg} \mathrm{g}^{-1}$. The MOF-199 sorbent had the highest absorption rate [24]. In 2019, Vikrant et al. Examined conventional adsorbents such as activated carbon for the adsorption of gaseous benzene compared to the new adsorbent of the metal-organic framework. The results showed the highest efficiency of MOF-199 was $94.8 \mathrm{mg} \mathrm{g}^{-1}$, which was slightly higher than the other adsorbent, activated charcoal $\left(93.5 \mathrm{mg} \mathrm{g}^{-1}\right)$. Also, the adsorption efficiency of the adsorbent MOF(UiO-66) is 27.1 $\mathrm{mg} \mathrm{g}^{-1}$, which is lower than the activated charcoal adsorption efficiency [25]. In 2011, Young and colleagues studied the adsorption of VOCs by the metal-organic framework, MIL-101(Cr), influenced by the shape and size of the molecule and concluded that benzene adsorption capacity in MIL-101 was $1291 \pm 77 \mathrm{mg} \mathrm{g}^{-1}$ [21]. Ahmaruzzaman and Xiang et al showed that activated carbon has desirable physical and chemical properties, which made it useful as an adsorbent and was used in the industry for decades. Sone et al were reported the CNTs can be used for BTEX removal from the air. They showed the carbon nanotubes are promising better absorbed than other carbon materials due to their unique properties. The CNT has been defined as cylindrical porous with walls made of crystalline graphite layers. Many technologies, such as bio-filter system [26], surface interaction [27], separation [28], adsorption [29, 30], and nanocatalyst [31], were used for VOCs removal. In addition, the various adsorbents such as activated carbon based on cellulose acetate [32], carbon nanotube (MWCNTs) [33], Zeolite [34], the graphene-modified by IL [35] were reported for removal benzene and BTX from the air.

In this study, benzene vapour was removed from the air based on a tantalum metal-organic framework (Ta-MOF) by the gas flow solid-phase interaction (GF-SPI). Benzene adsorption based on Ta-MOF was evaluated in the static and dynamic systems. The benzene concentration was analyzed by the GC-FID. The main parameters such as temperature, flow rate, the adsorbent mass and benzene concentration were optimized.

\section{Material and Methods}

\subsection{Instrumental and reagents}

All of the chemical compounds such as benzene anhydrous (99.8\%, CAS N.: 71-43-2), tantalum chloride (CAS N: 7721-01-9 $\mathrm{TaCl}_{5}$ ), benzene tetracarboxylic acid (CAS N.: 8905-4), the cetyltrimethylammonium-Bromide (CAS N.: 57-09-0), and propane had high purity and were purchased from the Merck/Sigma company(Germany). Five calibration solutions of benzene were prepared. The approximate concentrations of benzene were prepared from 0.1 , $0.5,1.0,1.5$, and $2.0 \%(\mathrm{v} / \mathrm{v})$. The other chemicals 


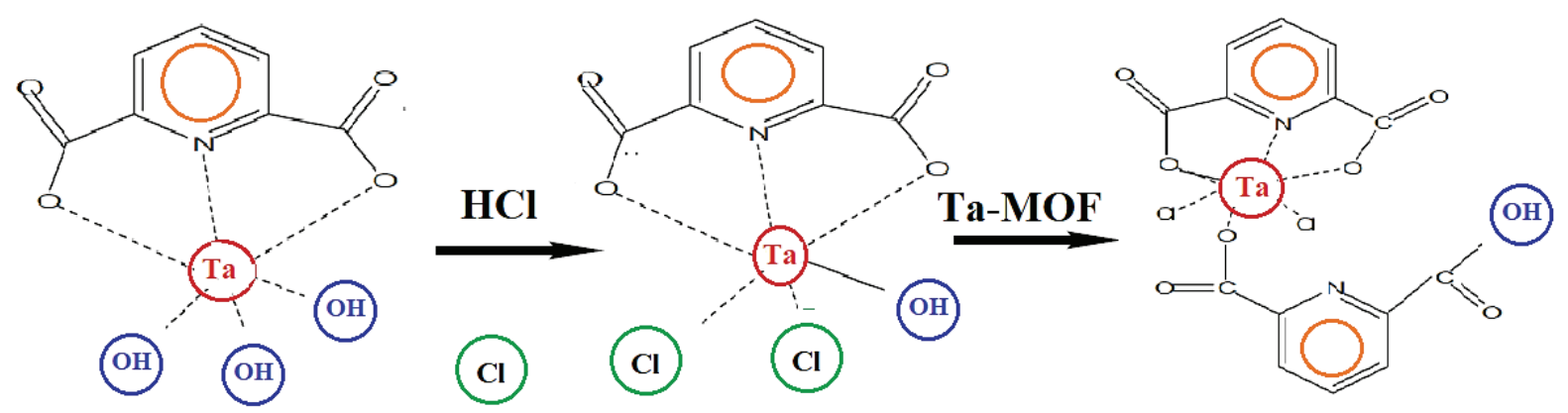

Fig.1. Preparation steps for synthesis of the tantalum metal-organic framework

based on GC grade and $99 \%$ purity were purchased from Merck (Germany). The characterization of the synthesized MOF was carried out via SEM-Philips XL 30, UK, and the X-ray diffraction equipment (XRD) Rigaku XDS 2000. The Agilent 7890A $\mathrm{GC}$ based on three detectors was used for benzene determination. The FID detector chosen was selected for benzene analysis in air. For injecting, slide the plunger carrier down and tighten the plunger thumb screw. Due to sampling valves, we introduce a sample of fixed size into the carrier gas stream. Valves are most frequently used to sample air or liquids. Gas sampling bags with valve and septum port (Tedlar) and air sampling apparatus (Bucket brigade) were prepared. The split/splitless injector, FID, and a column coated $(50 \mathrm{~m} \times 0.2 \mathrm{~mm}$ id.) was used by GC. The injector temperature was adjusted to $200-210^{\circ} \mathrm{C}$ and the detector temperature at $240-250^{\circ} \mathrm{C}$. The $\mathrm{GC}$ oven temperature was tuned at $220^{\circ} \mathrm{C}$. Hydrogen as the carrier gas was used at a flow rate of $1.0 \mathrm{~mL}$ min with a split ratio of 1:100. Vials with PTFE air-tight cap (parker) were used as a batch/static system.

\subsection{Preparation of the tantalum metal-organic framework}

In this study, the MOF adsorbent was prepared by Rezaie and colleagues' research [36]. A solution of tantalum chloride $(0.027 \mathrm{~g})$ and benzene tetracarboxylic acid $(0.011 \mathrm{~g})$ was prepared in 17 $\mathrm{mL}$ double distilled water (DDW). The solution prepared from the reaction above and then added to the mixture of $0.77 \mathrm{~g}$ cetyltrimethylammoniumBromide and $8 \mathrm{~mL}$ propane in a $50 \mathrm{~mL}$ Pyrex tube.
This new compound is then put in a microwave bath of $45^{\circ} \mathrm{C}$ and microwave bath with a power of 220 watts for 30 minutes. After 45 minutes of centrifuging, the MOF white crystals were formed, and then the product was left to dry in an argon atmosphere (Fig.1).

\subsection{Benzene preparation in a dynamic system}

First, the air was purified with an electro air cleaner (EA-HEPA600M) based on HEPA and activated carbon which was removed particles 200-300 nm (99.97\%) and VOCs from the air, respectively. Then, the pure air passed through the chamber and entered to PVC bag (5 Li) by an SKC pump. The amount of $\mathrm{H}_{2} \mathrm{O}$ (vapor) was controlled by adjusting the amount of water injection. All of the gas lines and bags were covered with heating jackets at 50$60{ }^{\circ} \mathrm{C}$ to prevent $\mathrm{H}_{2} \mathrm{O}$ (vapor) and benzene from condensing (Fig.2).

\subsection{Static and dynamic adsorption procedure}

For the static experiment, $10 \mathrm{~mL}$ of different concentrations of benzene were drawn with a syringe and injected into the vials that were air-tightened with a PTFE lid and contained the Ta-MOF adsorbent. After a specific time, 100-500 microliter air from the vial was extracted and injected into the GC-FID analyzer for determining benzene. The effect of four exposures, times $(5,10,15$, and 20 minutes), the amount of Ta-MOF adsorbent in four amounts $(0.5,1,1.5$, and $2 \mathrm{mg})$, four different concentration levels (30, 50, 70, and $100 \mathrm{mg} \mathrm{L}^{-1}$ of benzene) and, two temperatures of 25 and $45^{\circ} \mathrm{C}$ based on Ta-MOF adsorbent were studied (Fig.3). 


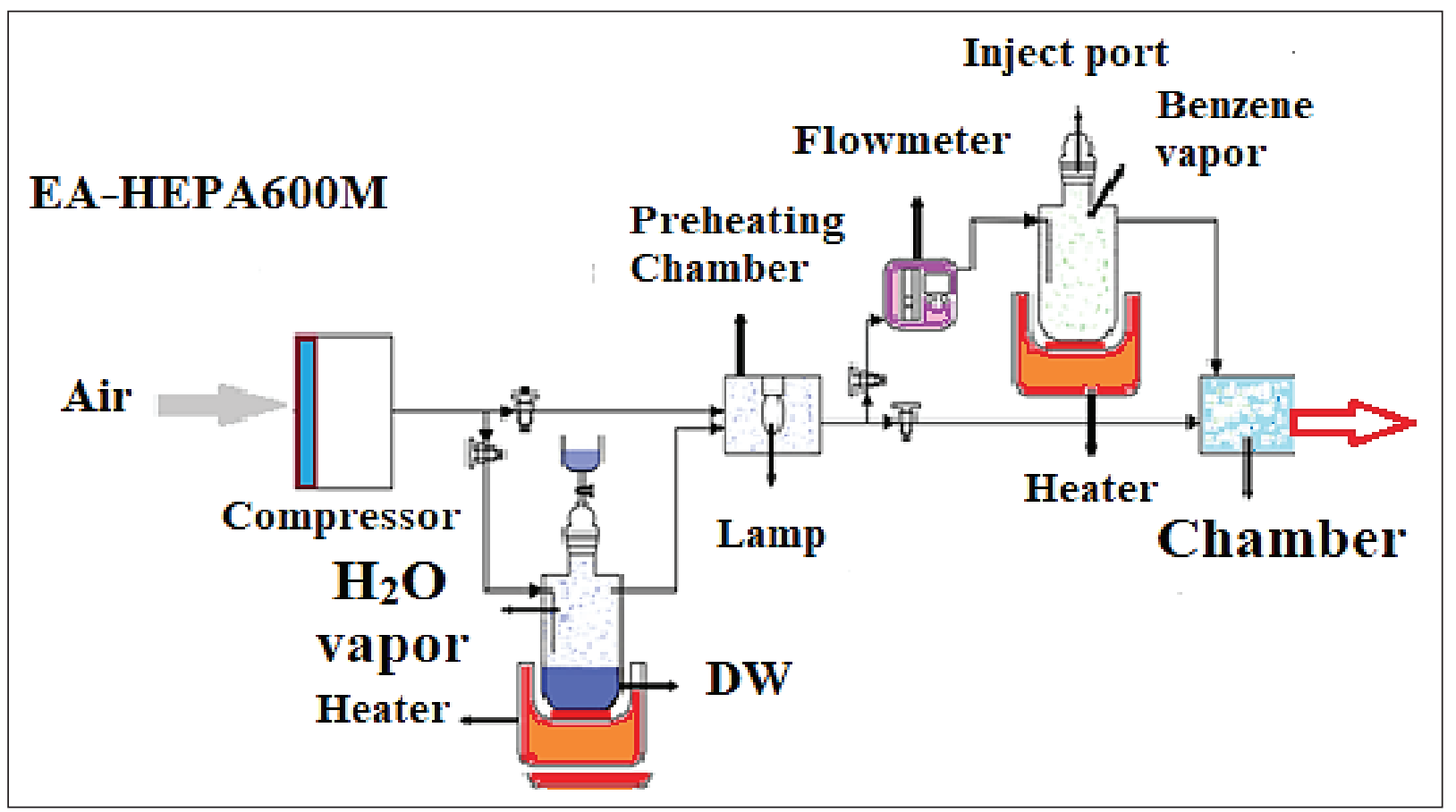

Fig.2. The generation of benzene vapor in pure air by chamber

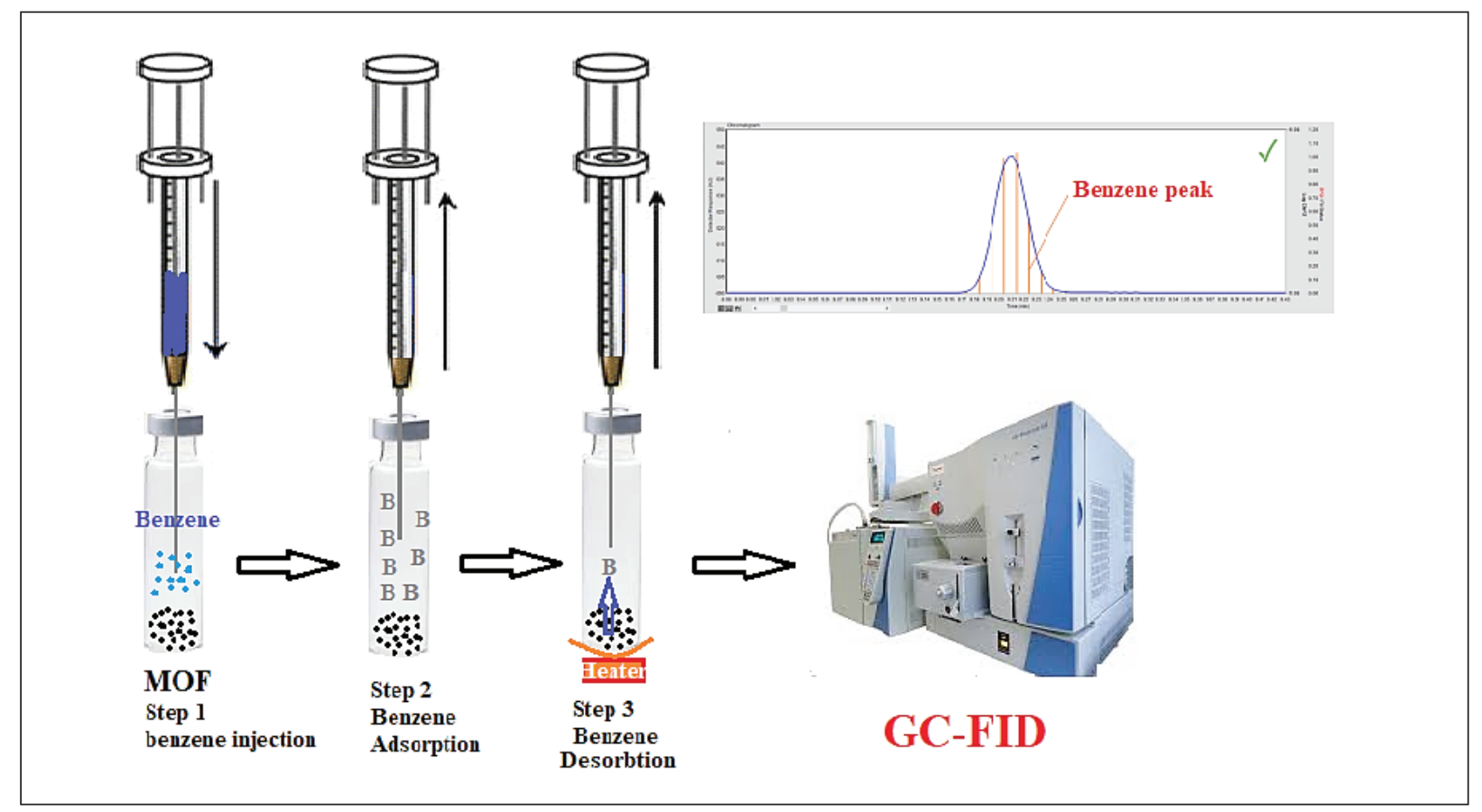

Fig.3. Static procedure for benzene removal from air by the Ta-MOF adsorbent 


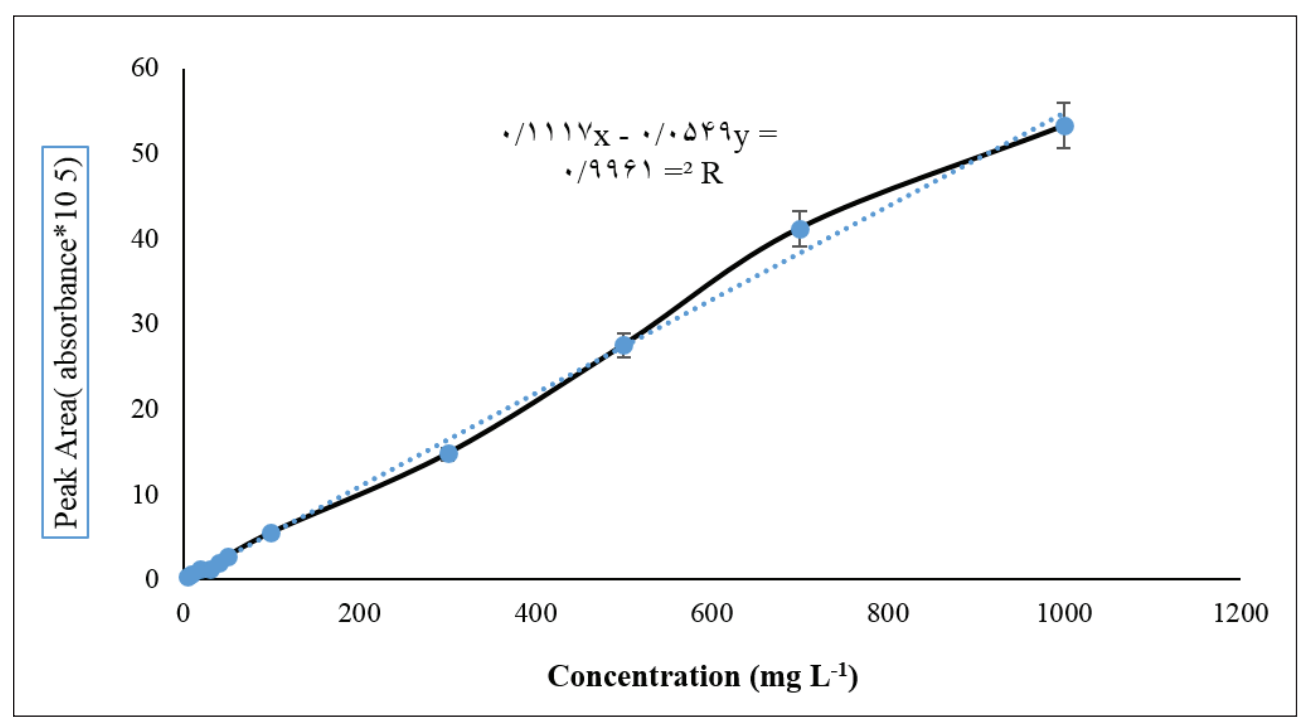

Fig.4. The calibration curve of benzene based on Ta-MOF adsorbent by GC-FID

The adsorption efficiency for static adsorption was obtained from the following equation:

$$
Q=\frac{\left(C_{0}-C_{e}\right) \times V}{m}
$$

In the equation, $\mathrm{Q}$ is adsorption efficiency in (mg $\left.\mathrm{g}^{-1}\right), \mathrm{C}_{0}$ is benzene's primary concentration in ( $\mathrm{mg}$ $\left.\mathrm{L}^{-1}\right), \mathrm{C}_{\mathrm{e}}$ is benzene's equilibrium concentration in the vial in $\left(\mathrm{mg} \mathrm{L}^{-1}\right), \mathrm{m}$ is the amount of adsorbent in $(\mathrm{g})$, and $\mathrm{V}$ is the vial's volume in $(\mathrm{L})$.

To draw the calibration curve from different standard concentrations of benzene in the ranges between 10 - $1000 \mathrm{mg} \mathrm{L}^{-1}$ were prepared in Tedlar sampling bags. Then, 100-500 microliters of the air vial containing benzene were prepared by a micro GC syringe. At last, the calibration curve was plotted by considering standard solutions and adsorption peak areas by GC-FID (Fig.4).

By dynamic procedure, $20 \mathrm{mg}$ of Ta-MOF sorbent tubes connected to a sampling pump (SKC, UK). The flow rate was adjusted to $50-400 \mathrm{~mL} \mathrm{~min}^{-1}$. The benzene vapour was mixed with pure air in the chamber, the different value of benzene in the air was passed through the Ta-MOF sorbent. After adsorption of benzene on Ta-MOF, the adsorbent was heated by thermal accessory at $80-100{ }^{\circ} \mathrm{C}$ in the presence of $\mathrm{Ar}$ gas and then, the benzene was desorbed from Ta-MOF and flowed/stored in a polyethylene bag. Finally, the $100-500$ microliters of air were aspired with Hamilton syringes and injected into an injector of GC-FID. Based on the dynamic procedure, Ta-MOF had efficient extraction and recovery for the removal of benzene from the air. The results showed that the absorption capacity of the static system was higher than the dynamic system at a flow rate of $250 \mathrm{ml} \mathrm{min}^{-1}$.

\section{Results and Discussion}

\subsection{SEM, TEM and XRD analysis}

The morphology and size distribution of Ta-MOF nanoparticles were studied by a scanning electron microscope (SEM) and transmission electron microscopy (TEM). In this study, characterization of tantalum MOF adsorbent was carried out by SEM, TEM and XRD devices. SEM's microscopic images of Ta-MOF showed that the average size of particles in tantalum MOF adsorbent is 48 nanometers (Fig.5a). TEM of Ta-MOF showed a nanometric size of about $30 \mathrm{~nm}$. The Ta-MOF sample has homogenous morphology with similar particle size (Fig.5b). Also, XRD images showed that tantalum MOF adsorbent has a cubic crystal structure (Fig.6). the X-ray diffraction pattern of porous TaMOF that prepared by the ultrasonic method. A comparison of Ta-MOF diffraction with the other MOF revealed a triclinic crystalline structure of Ta- 


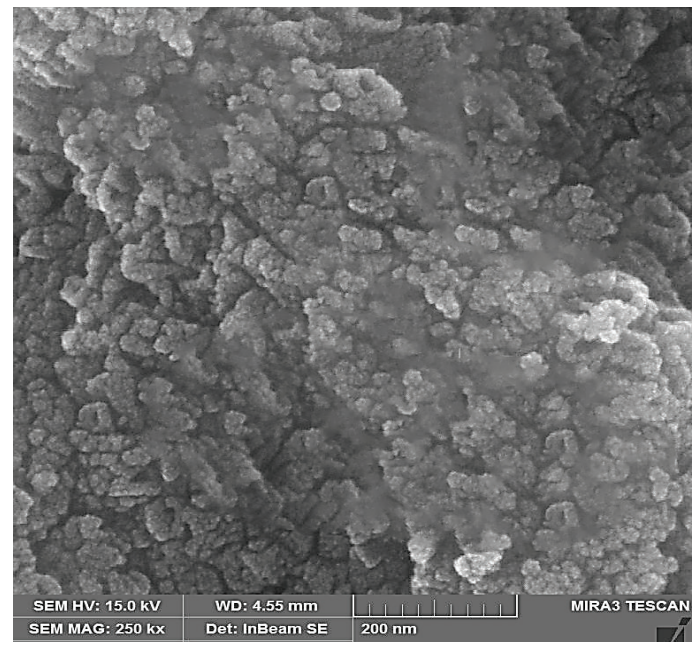

Fig. 5a. SEM images of tantalum Ta-MOF

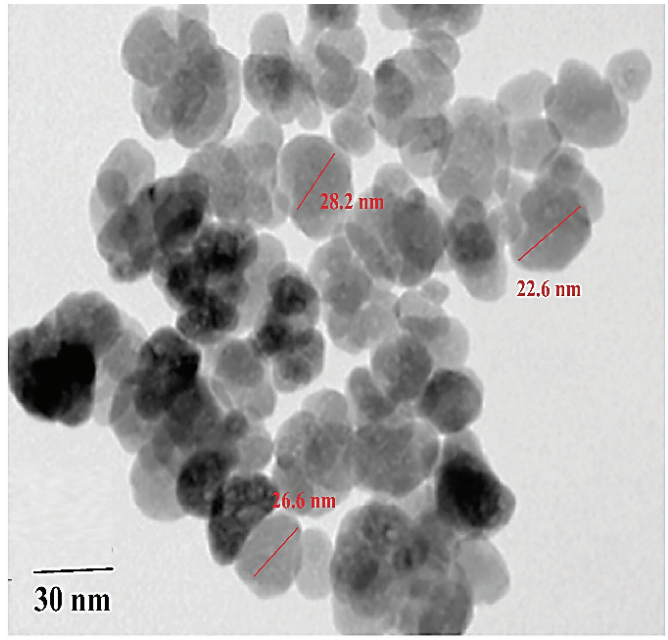

Fig. 5b. TEM images of tantalum Ta-MOF

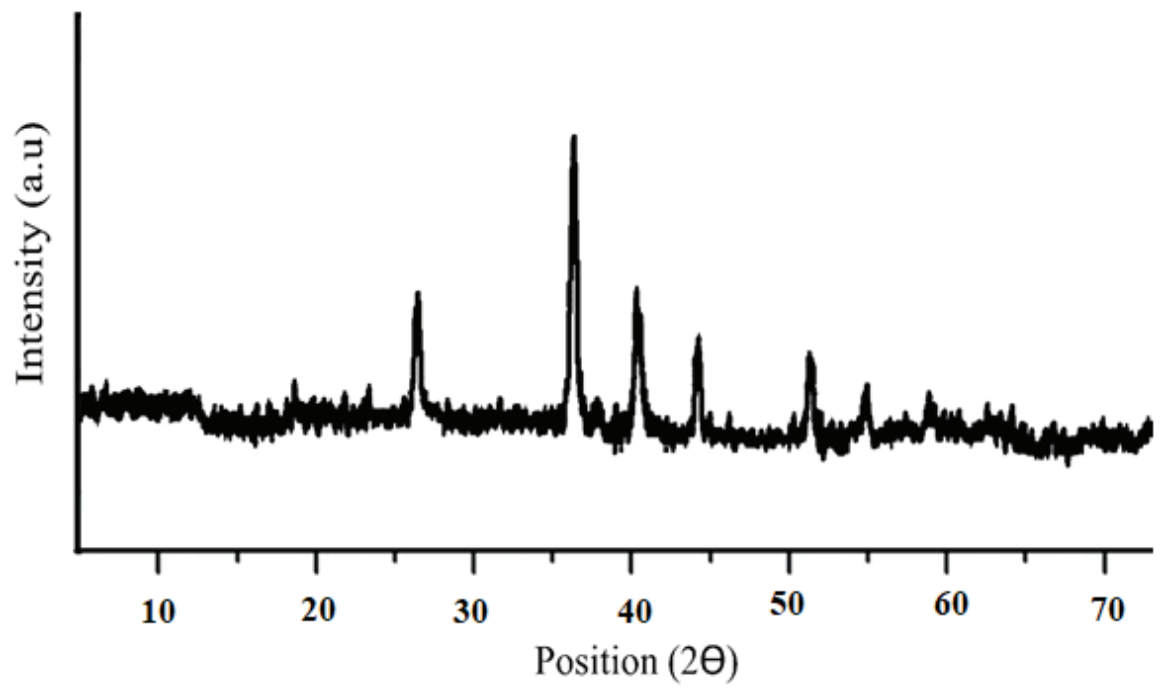

Fig. 6. XRD images of the tantalum MOF adsorbent

MOF. As TEM images any agglomeration wasn't seen in the structure of Ta-MOF.

\subsection{The effect of benzene concentration on adsorption efficiency}

The effect of benzene's primary concentration varying from 10 to $100 \mathrm{mg} \mathrm{L}^{-1}$ on tantalum MOF adsorbent was studied. The results showed tantalum adsorbent became saturated at a concentration of $70 \mathrm{mg} \mathrm{L}^{-1}$ (Fig. 7).

\subsection{The Effect of exposure time on adsorbent efficiency}

The effect of different times from 5 to 20 minutes for benzene removal based on tantalum MOF in different concentrations of benzene between 10-100 mg L-1 was studied. In this study, it was observed that increasing the exposure time has a positive effect on the recovery and adsorption capacity of Ta-MOF adsorbent. The results showed, the adsorption rate increases up to 10 minutes and then remains almost constant (Fig.8).

\subsection{The effect of the amount of Ta-MOF on adsorption efficiency}

The effect of the amount of the adsorbent (Ta-MOF) in the range of 0.1 to $2 \mathrm{mg}$ for benzene removal include the benzene concentration $\left(10-100 \mathrm{mg} \mathrm{L}^{-1}\right)$ 


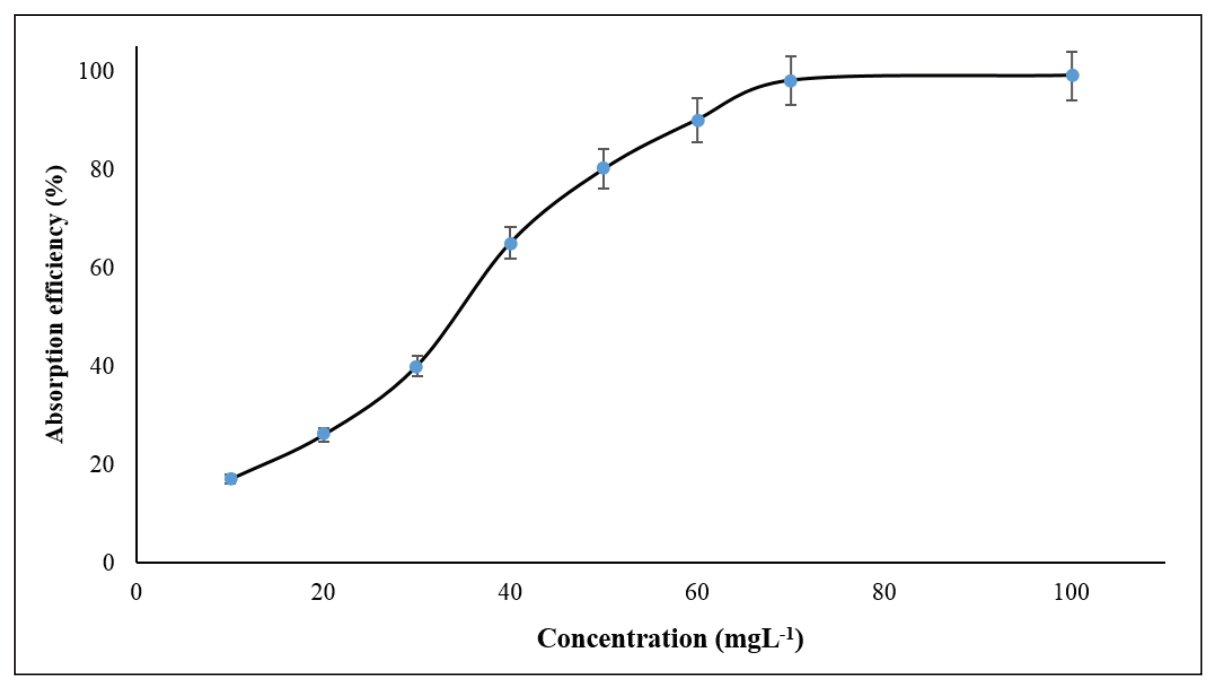

Fig.7. The effect of benzene concentration on Ta-MOF adsorption efficiency

was studied in optimized conditions. The results showed the maximum adsorption efficiency for benzene was achieved for $0.5 \mathrm{mg}$ of Ta-MOF by $70 \mathrm{mg} \mathrm{L}^{-1}$. Due to Figure 9, for an extra amount of adsorbent, the adsorption capacity increased and then constant (Fig. 9).

\subsection{The effect of temperature on adsorption efficiency of Ta-MOF}

For efficient removal of benzene from the air, the effect of temperature on adsorption/desorption of Ta-MOF must be optimized. The results showed us, the optimized temperature for adsorption and desorption of benzene from sorbent was achieved at $45{ }^{\circ} \mathrm{C}$ and $90{ }^{\circ} \mathrm{C}$, respectively. The effect of temperature on benzene removal was studied in optimized conditions. For this purpose, the different concentrations of benzene in the range of 10 to $100 \mathrm{mg} \mathrm{L}^{-1}$ of benzene at a temperature between $25-60^{\circ} \mathrm{C}$ were evaluated. The results showed us, the maximum absorption capacity and efficiency were obtained at the temperature of $45{ }^{\circ} \mathrm{C}$. For evaluating, 100-500 microliters of air containing benzene in static and dynamic procedure injected into GC. As shown in Figure 10, by increasing temperature, the absorption capacity and efficiency decreased (Fig.10).

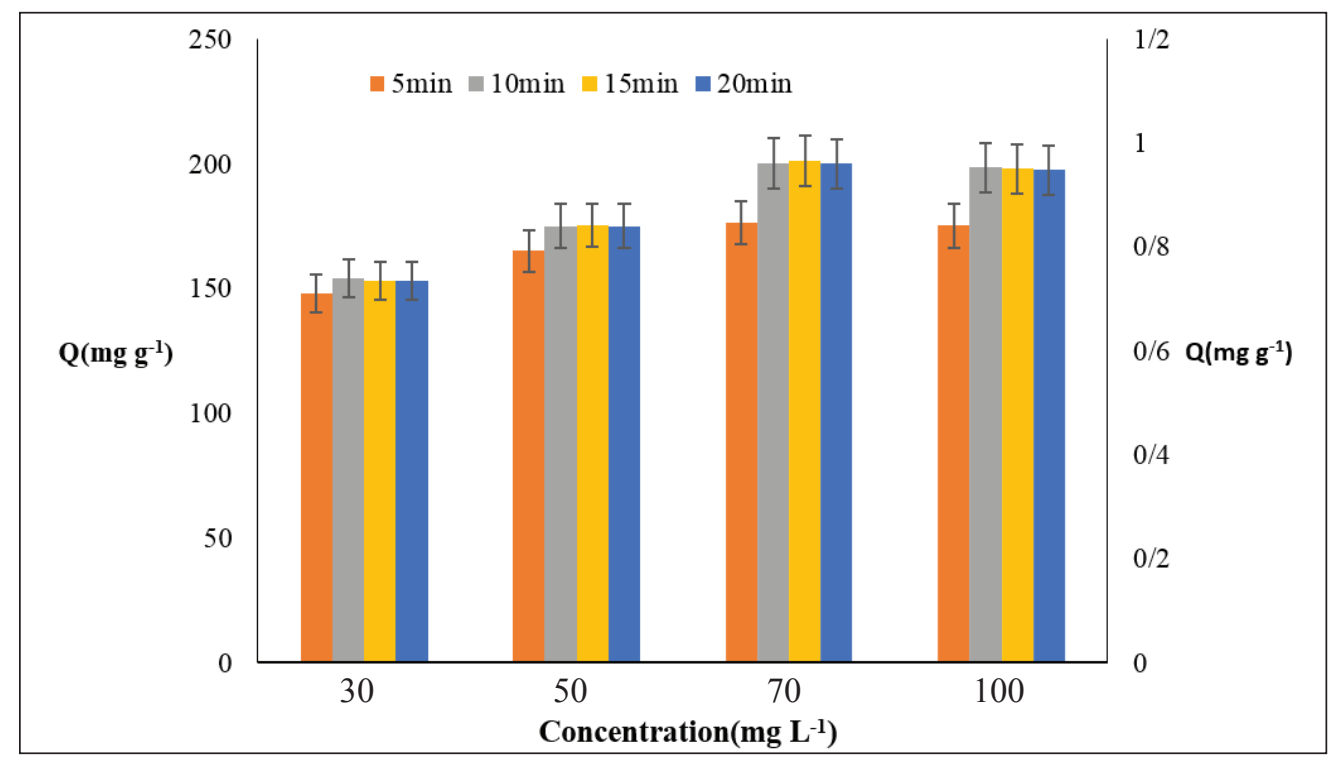

Fig. 8. The Effect of exposure time on adsorbent efficiency 


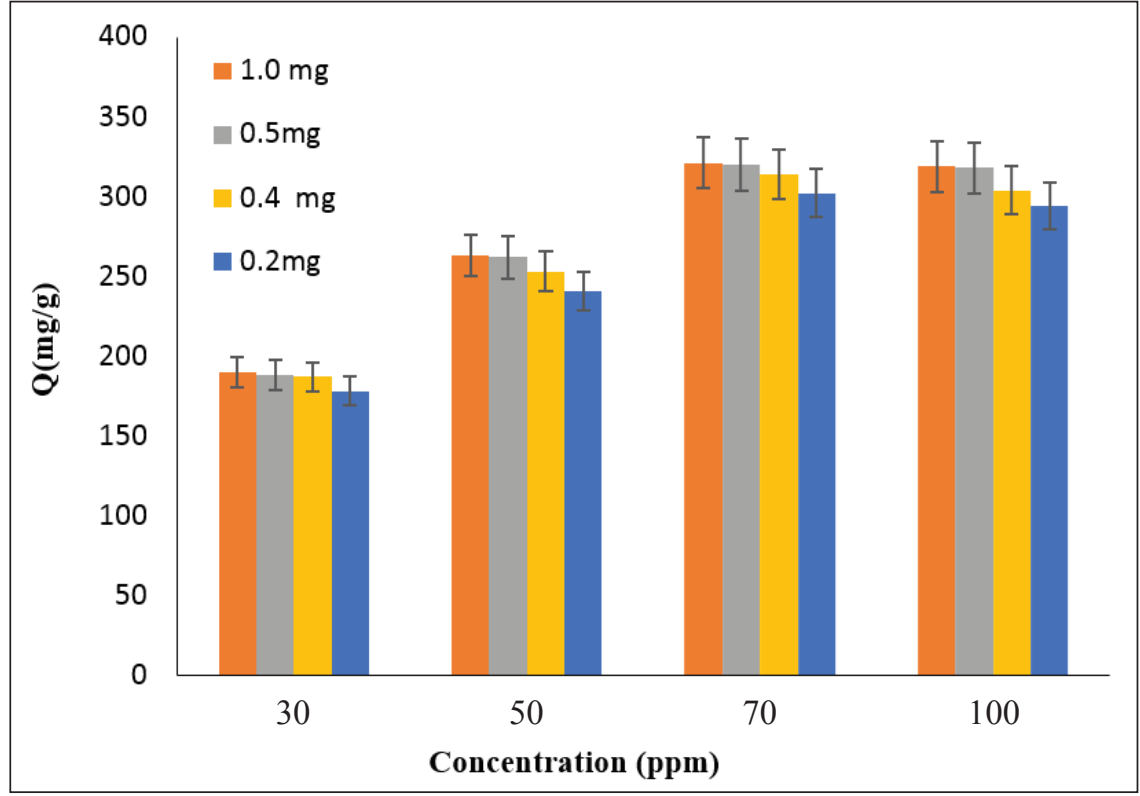

Fig. 9. The effect of the amount of Ta-MOF on adsorption capacity
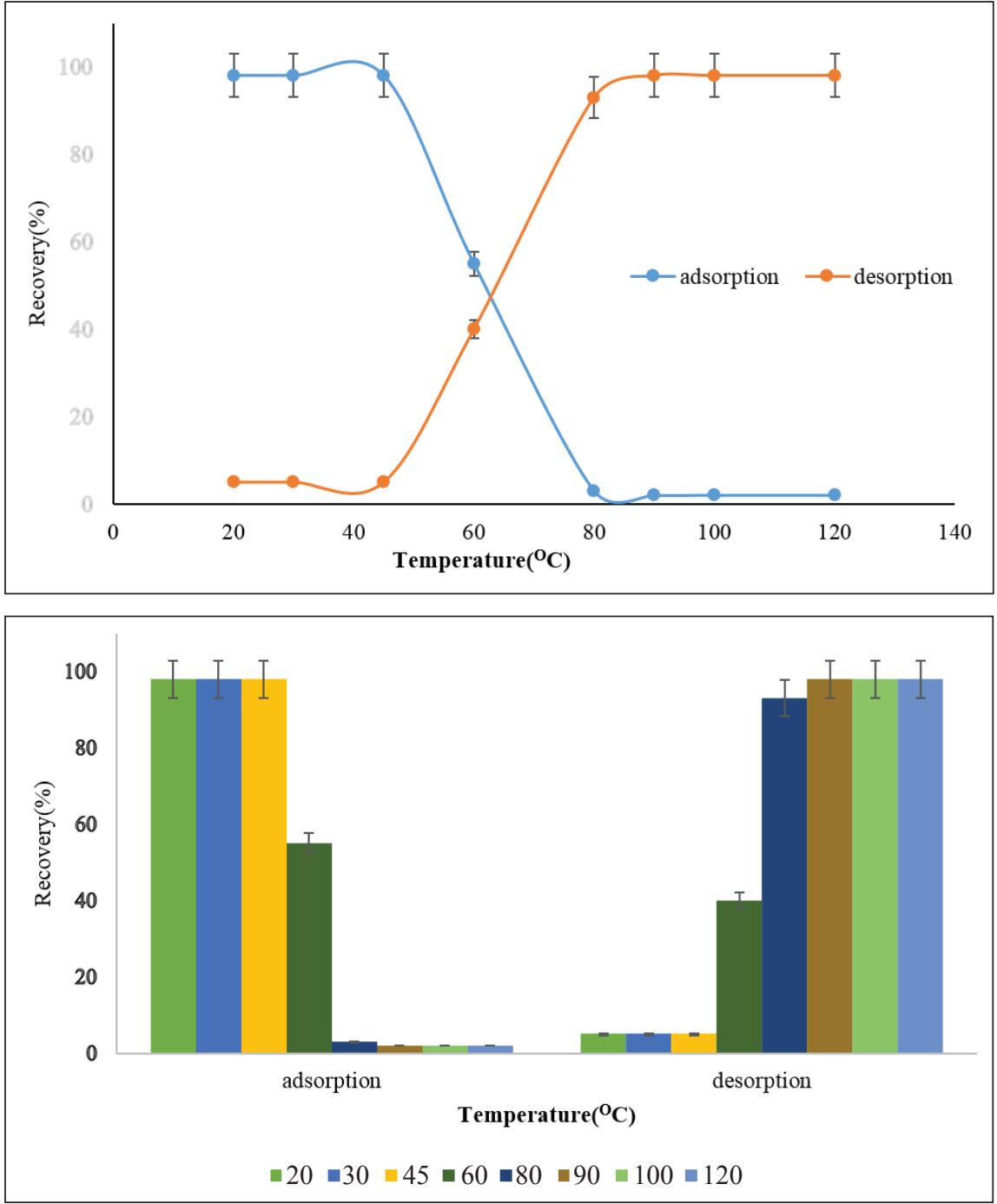

Fig.10. The effect of temperature on adsorption efficiency of Ta-MOF 


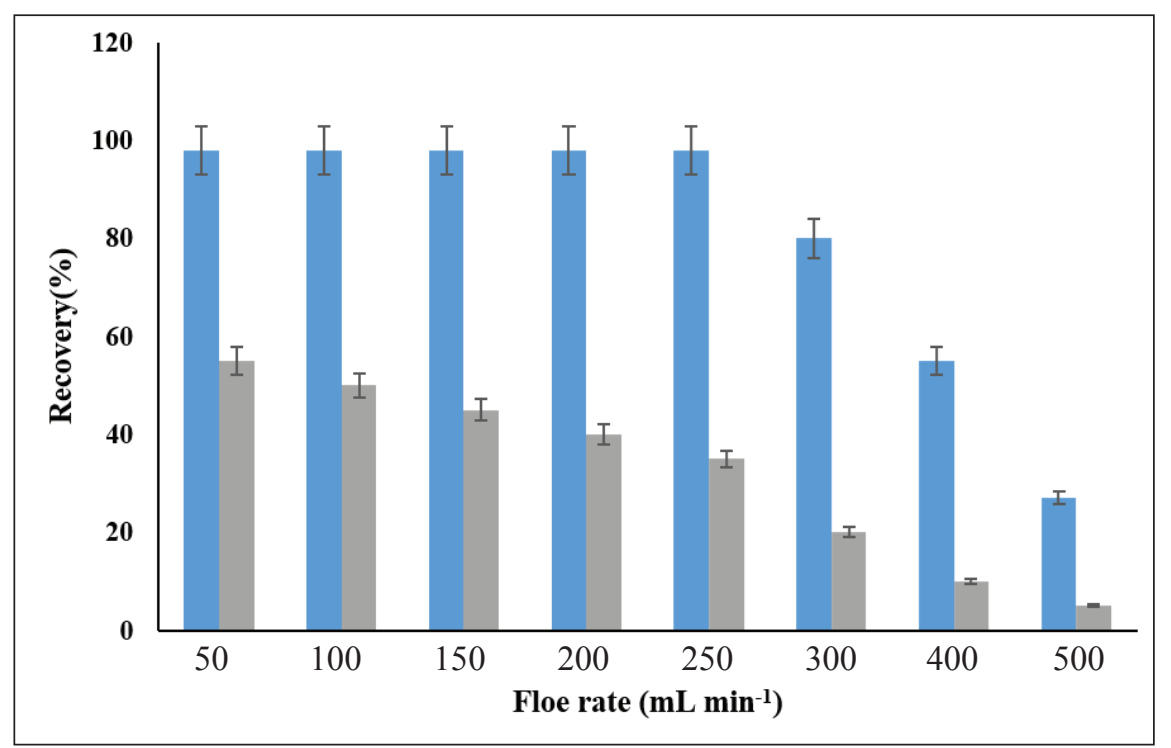

Fig.11. The effect of flow rate on adsorption efficiency of Ta-MOF (blue, $45^{\circ} \mathrm{C}$; grey, $60{ }^{\circ} \mathrm{C}$ )

\subsection{Effect of flow rate}

By procedure, the effect of different flow rates between $50-500 \mathrm{~mL} \mathrm{~min}{ }^{-1}$ was studied by TaMOF adsorbent. The flow rate was measured by a digital rotameter. The removal efficiency and adsorption capacity of Ta-MOF were reduced in more than $300 \mathrm{~mL} \mathrm{~min}^{-1}$ of flow rate. So, 250 $\mathrm{mL} \mathrm{min}^{-1}$ of flow rate was used as optimum flow rate for removal of benzene from the air. A higher flow rate was significantly reduced the adsorption efficiency of benzene. Figure 11 shows the removal efficiency and adsorption capacity decreased by increasing the flow rate in optimized temperature (blue, $45^{\circ} \mathrm{C}$ ). Therefore, benzene cannot absorb at a higher flow rate by the sorbent. The results showed us the removal efficiency and the adsorption capacity was decreased at $60{ }^{\circ} \mathrm{C}$ (grey).

Table 1. Validation of GF-SPI method in a dynamic system based on Ta-MOF adsorbent by spiking benzene (ppm)

\begin{tabular}{|c|c|c|c|}
\hline \multirow{2}{*}{ Air Samples } & \multicolumn{3}{|c|}{ GF-SPI, GC-FID } \\
\hline & Added(ppm) & ppm & Recovery (\%) \\
\hline \multirow[t]{2}{*}{ A } & ---- & $11.9 \pm 0.4$ & ---- \\
\hline & 10 & $21.7 \pm 1.1$ & 98.1 \\
\hline \multirow[t]{2}{*}{ B } & ---- & $18.5 \pm 0.8$ & ---- \\
\hline & 20 & $38.2 \pm 1.7$ & 98.5 \\
\hline \multirow[t]{2}{*}{$\mathrm{C}$} & ---- & $31.7 \pm 1.4$ & ---- \\
\hline & 30 & $61.9 \pm 2.9$ & 100.6 \\
\hline
\end{tabular}

${ }^{\mathrm{a}}$ Mean of three determinations \pm confidence interval $(\mathrm{P}=0.95, \mathrm{n}=5)$ 


\subsection{Validation of methodology}

The Ta-MOF was used for the removal of benzene vapour from the air. By the proposed method, a mixture of 10-100 ppm of benzene vapour in pure air (Ar gas) was passed through Ta-MOF sorbent by an SKC pump. Before adsorption, the standard of benzene in the air was validated by GC-MS in different concentrations. For validation, the spiked benzene concentration was done to demonstrate the reliability of the method by Ta-MOF (Table 1). At optimized conditions, at different times based on $250 \mathrm{mLmin}^{-1}$, the different concentrations of benzene in the air were generated and used for validation by spiking samples. The efficient recovery of spiked samples confirmed the capability of flow solid-phase interaction (GF-SPI) for the removal of benzene from the air.

\subsection{Discussion}

MOF adsorbent is one of the strongest adsorbents regarding the removal of volatile compounds from the air. In this study, the effect of tantalum organic metal framework adsorbent (Ta-MOF) for the removal of benzene vapour was investigated. The efficiency of different MOF adsorbents for benzene adsorption is shown in Table 2. Due to results, the tantalum MOF adsorbent has a higher adsorption efficiency as compared to the other adsorbents. In 2010, Lu and colleagues conducted a study regarding the removal of benzene, toluene, ethylbenzene, and para-xylene with carbon nanotubes oxidized by sodium hypochlorite and concluded that at first, with the increase of exposure time, benzene adsorption efficiency also increased and then decreased [37]. As compared to the Ta-MOF, by increasing exposure time, the adsorption efficiency increased. Moreover, the maximum amount of adsorption occurred at 10 minutes and then the amount of adsorption remained constant. Also, in 2018, Hua Xie and colleagues carried out a study and concluded that the increase in temperature when using the MOF adsorbent, BUT-66 (Zr), lowered adsorption efficiency. In this study, it was found that the adsorbent at 25 and $80^{\circ} \mathrm{C}$ had $2.54 \mathrm{mmol} \mathrm{g}^{-1}$ and $1.65 \mathrm{mmol} \mathrm{g}^{-1}$ of benzene adsorption, respectively [5], while in the present study at 25 and $45^{\circ}$ $\mathrm{C}$, by increasing temperature, the amount of adsorption has decreased slightly. Also, the effect of temperature in the different adsorbents such as nano activated carbons and activated carbon has also been observed, which is confirmed by the study of Golbabai et al. to remove xylene vapor by these adsorbents. The results from Bright and colleagues research in 2008 regarding benzene adsorption efficiency using the adsorbents such as (MOF-5) ( $\mathrm{Zn} 4 \mathrm{O}(\mathrm{CO} 2) 6)$, (MOF-3) $\left(\mathrm{C}_{8} \mathrm{H}_{5} \mathrm{NO}_{4}-2\right)$, $(\mathrm{MOF}-177) \quad\left(\mathrm{Zn}_{4} \mathrm{O}(\mathrm{btb})_{2}\right)$ and (MOF-199) $\left(\mathrm{Cu}_{2}\left(\mathrm{CO}_{2}\right)_{4}\right)$, at benzene concentration levels of $440 \mathrm{ppm}$, showed that benzene adsorption efficiency for each $1 \mathrm{gr}$ adsorbent, was 2, 56, 1, and 176 milligrams of benzene, respectively [38]. However, in the present study, a trace amount of Ta-MOF can be absorbed by a high concentration of benzene (70 ppm) with a significant adsorption rate of $155.3 \mathrm{mg} \mathrm{g}^{-1}$ which indicated the high adsorption capacity of the Ta-MOF adsorbent.

Table2. Comparing of adsorption capacities of Ta-MOF with other adsorbents

\begin{tabular}{|c|c|c|c|c|c|}
\hline Adsorbate & Adsorbents & $A_{\text {sur }}\left(m^{2} g^{-1}\right)$ & $\mathbf{Q}_{\mathrm{a}}$ & $\mathbf{T}$ & Refs. \\
\hline \multirow{8}{*}{ Benzene } & $\left(\mathrm{Zn}_{4} \mathrm{O}\left(\mathrm{CO}_{2}\right)_{6}\right) \mathrm{MOF}-5$ & 2205 & $2 \mathrm{mg} \mathrm{g}^{-1}$ & $25^{\circ} \mathrm{c}$ & {$[24]$} \\
\hline & $\left(\mathrm{C}_{8} \mathrm{H}_{5} \mathrm{NO}_{4}-2\right)$ IRMO-3 & 1568 & $56 \mathrm{mg} \mathrm{g}^{-1}$ & $25^{\circ} \mathrm{c}$ & {$[24]$} \\
\hline & $\left(\mathrm{Zn}^{2} \mathrm{O}_{2}\left(\mathrm{CO}_{2}\right)_{2}\right) \mathrm{MOF}-74$ & 632 & $96 \mathrm{mg} \mathrm{g}^{-1}$ & $25^{\circ} \mathrm{c}$ & {$[24]$} \\
\hline & $\left(\mathrm{Zn}_{4} \mathrm{O}(\mathrm{btb})_{2}\right) \mathrm{MOF}-177$ & 3875 & $1 \mathrm{mg} \mathrm{g}^{-1}$ & $25^{\circ} \mathrm{c}$ & {$[25]$} \\
\hline & $\left(\mathrm{Cu}_{2}\left(\mathrm{CO}_{2}\right)_{4}\right) \mathrm{MOF}-199$ & 1264 & $176 \mathrm{mg} \mathrm{g}^{-1}$ & $25^{\circ} \mathrm{c}$ & {$[24,25]$} \\
\hline & IRMO-62 & 1814 & $109 \mathrm{mg} \mathrm{g}^{-1}$ & $25^{\circ} \mathrm{c}$ & {$[24]$} \\
\hline & MIL-101 (Cr) & 3980 & $1291 \pm 77 \mathrm{mg} \mathrm{g}^{-1}$ & $25^{\circ} \mathrm{c}$ & {$[17]$} \\
\hline & Ta-MOF & 1200 & $350 \mathrm{mg} \mathrm{g}^{-1}$ & $45^{\circ} \mathrm{c}$ & This study \\
\hline
\end{tabular}




\section{Conclusion}

In the present study, a new Ta-MOF adsorbent was used for the removal of benzene from air and the absorption efficiency studied. For benzene analysis, 100-500 microliter air from the vial (static) or polyethylene bag (dynamic) was extracted and injected into the GC-FID analyzer. To evaluate the adsorbent capacity, the effect of four independent factors such as benzene concentration, the adsorbent amount, the exposure time, and temperature on the amount of benzene adsorption were investigated. The absorption capacities of static and dynamic procedures based on Ta-MOF were obtained $155.3 \mathrm{mg} \mathrm{g}^{-1}$ and $124.6 \mathrm{mg} \mathrm{g}^{-1}$, respectively based on $0.5 \mathrm{~g}$ of Ta-MOF and the flow rate of $250 \mathrm{~mL} \mathrm{~min}^{-1}$. The results showed the Ta-MOF adsorbent had more adsorption capacity than other conventional adsorbents.

\section{Acknowledgements}

The authors wish to thank the Department of Occupational Health and Safety at Work, Kerman University of Medical Sciences, Kerman, Iran for supporting this work.

\section{References}

[1] G. Zhang, Y. Liu, S. Zheng, Z. Hashisho, Adsorption of volatile organic compounds onto natural porous minerals, J. Hazard. Mater., 364 (2019) 317-324. https://doi. org/10.1016/j.jhazmat.2018.10.031.

[2] P. Liu, C. Long, Q. Li, H. Qian, A. Li, Q. Zhang, Adsorption of trichloroethylene and benzene vapors onto hypercrosslinked polymeric resin, J. Hazard. Mater., 166 (2008) 46-51. https://doi.org/10.1016/j. jhazmat.2008.10.124.

[3] D. Loomis, K.Z. Guyton, Y. Grosse, F. El Ghissassi, V. Bouvard, L. BenbrahimTallaa, N. Guha, N. Vilahur, H. Mattock, K. Straif, Carcinogenicity of benzene, Lancet. Oncol, 18 (2017) 1574-1575. https://doi. org/10.1016/s1470-2045(17)30832-x.

[4] R. Althouse, J. Huff, L. Tomatis, J. Wilbourn, Chemicals and industrial processes associated with cancer in humans. IARC Monographs,
IARC. Monogr. Eval. Carcinog. Risk. Chem. Hum. Suppl., 1-20 (1979) 1-71. https://monographs.iarc.who.int/wp-content/ uploads/2018/06/mono71.pdf

[5] L.H. Xie, X. M. Liu, T. He, J. R. Li, MetalOrganic frameworks for the capture of trace aromatic volatile organic compounds, Chem., 4 (2018) 1911-1927. https://doi. org/10.1016/j.chempr.2018.05.017.

[6] P. Gaurh, H. Pramanik, Production of benzene/ toluene/ethyl benzene/xylene (BTEX) via multiphase catalytic pyrolysis of hazardous waste polyethylene using low-cost fly ash synthesized natural catalyst, Waste. Manag., 77 (2018) 114-130. https://doi.org/10.1016/j. wasman.2018.05.013.

[7] D.M.Chambers, C.M. Reese, L.G. Thornburg, E. Sanchez, J.P. Rafson, B.C. Blount, J.R.E. Ruhl, V.R. De Jesús, Distinguishing petroleum (Crude Oil and Fuel) from smoke exposure within populations based on the relative blood levels of benzene, toluene, ethylbenzene, and xylenes (BTEX), styrene and 2,5-Dimethylfuran by pattern recognition using artificial neural networks, Environ. Sci. Technol., 52 (2018) 308-316. https://doi. org/10.1021/acs.est.7b05128.

[8] E. Farsouni Eydi, A. Shariati, M.R. KhosraviNikou, Separation of BTEX compounds (benzene, toluene, ethylbenzene and xylenes) from aqueous solutions using adsorption process, J. Dispers. Sci. Technol., 40 (2019) 453-463. https://doi.org/10.1080/01932691.2 018.1472007.

[9] A.L. Bolden, C.F. Kwiatkowski, T. Colborn, New look at BTEX: Are ambient levels a problem?, Environ. Sci. Technol., 49 (2015) 5261-5276. https://doi.org/10.1021/es505316f.

[10] M.I. Konggidinata, B. Chao, Q. Lian, R. Subramaniam, M. Zappi, D.D. Gang, Equilibrium, kinetic and thermodynamic studies for adsorption of BTEX onto ordered mesoporous carbon (OMC), J. Hazard. Mater., 336 (2017) 249-259. https://doi. org/10.1016/j.jhazmat.2017.04.073. 
[11] R. Montero-Montoya, R. López-Vargas, O. Arellano-Aguilar, Volatile organic compounds in air: sources, distribution, exposure and associated illnesses in children, Ann. Glob. Health, 84 (2018) 225-238. https://doi.org/10.29024/aogh.910.

[12] F.A. Kuranchie, P.N. Angnunavuri, F. Attiogbe, E.N. Nerquaye-Tetteh, Occupational exposure of benzene, toluene, ethylbenzene and xylene (BTEX) to pump attendants in Ghana: Implications for policy guidance, Cogent. Environ. Sci., 5 (2019) 1603418. https://doi.org/10.1080/23311843. 2019.1603418.

[13] H. Huang, H. Huang, Q. Feng, G. Liu, Y.Zhan, M. Wu, H. Lu, Y. Shu, D.Y. Leung, Catalytic oxidation of benzene over Mn modified $\mathrm{TiO}_{2} /$ ZSM-5 under vacuum UV irradiation, Appl. Catal. B, 203 (2017) 870-878. https://doi. org/10.1016/j.apcatb.2016.10.083.

[14] W. Yang, H. Zhou, C. Zong, Y. Li, W. Jin, Study on membrane performance in vapor permeation of VOC/N2 mixtures via modified constant volume/variable pressure method, Sep. Purif. Technol., 200 (2018) 273-283. https://doi.org/10.1016/j.seppur.2018.02.044.

[15] V. Binas, V. Stefanopoulos, G. Kiriakidis, P. Papagiannakopoulos, Photocatalytic oxidation of gaseous benzene, toluene and xylene under UV and visible irradiation over Mn-doped $\mathrm{TiO}_{2}$ nanoparticles, J. Mater., 5 (2019) 56-65. https://doi.org/10.1016/j. jmat.2018.12.003.

[16] Y. Wang, H. Tao, D. Yu, C. Chang, Performance assessment of ordered porous electrospun honeycomb fibers for the removal of atmospheric polar volatile organic compounds, Nanomater. (Basel), 8 (2018) 350. https://doi.org/10.3390/nano8050350.

[17] K. Yang, Q. Sun, F. Xue, D. Lin, Adsorption of volatile organic compounds by metalorganic frameworks MIL-101: influence of molecular size and shape, J. Hazard. Mater., 195 (2011) 124-131. https://doi. org/10.1016/j.jhazmat.2011.08.020.
[18] K. Vellingiri, P. Kumar, A. Deep, K.H. Kim, Metal-organic frameworks for the adsorption of gaseous toluene under ambient temperature and pressure, Chem. Eng. J., 307 (2017) 1116-1126. https://doi. org/10.1016/j.cej.2016.09.012.

[19] W. Song, D. Tondeur, L. Luo, J. Li, VOC Adsorption in circulating gas fluidized bed, Adsorption, 11 (2005) 853-858. https://doi. org/10.1007/s10450-005-6035-z.

[20] Z. Zhao, S. Wang, Y. Yang, X. Li, J. Li, Z. Li, Competitive adsorption and selectivity of benzene and water vapor on the microporous metal organic frameworks (HKUST-1), Chem. Eng. J., 259 (2015) 79-89. https:// doi.org/10.1016/j.cej.2014.08.012.

[21] S. Gwardiak, B. Szczęśniak, J. Choma, M. Jaroniec, Benzene adsorption on synthesized and commercial metal-organic frameworks, J. Porous, Mater., 26 (2018) 775-783. https://doi.org/10.1007/s10934018-0678-0.

[22] L.Y. Filippova, V.N. Shubina, N.P. Kozlova, S.B. Putin, Adsorption properties of the MOF-5 metal-organic framework in relation to water and benzene, Russ. J. Appl. Chem., 86 (2013) 1388-1391. https:// doi.org/10.1134/S1070427213090126.

[23] Zhou H-C, Long JR, Yaghi OM, Introduction to Metal-Organic Frameworks, Chem. Rev., 112 (2012) 673-674. https://doi. org/10.1021/cr300014x.

[24] D. Britt, D. Tranchemontagne, O.M. Yaghi, Metal-organic frameworks with high capacity and selectivity for harmful gases, Proc. Natl. Acad. Sci., 105 (2008) 11623. https://doi.org/10.1073/pnas.0804900105.

[25] K. Vikrant, C. J. Na, S.A. Younis, K. H. Kim, S. Kumar, Evidence for superiority of conventional adsorbents in the sorptive removal of gaseous benzene under realworld conditions: Test of activated carbon against novel metal-organic frameworks, J. Clean. Prod., 235 (2019) 1090-1102. https:// doi.org/10.1073/pnas.0804900105. 
[26] D. Wu, X. Quan, Y. Zhao, S. Chen, Removal of p-xylene from an air stream in a hybrid biofilter, J. hazard. Mater., 136 (2006) 288-295. https://doi.org/10.1016/j. jhazmat.2005.12.017.

[27] S. Pedram, H.R. Mortaheb, F. Arefi-Khonsa, Optimization of benzene removal by air gap membrane distillation using response surface methodology, J. Water Supp. Res. Technol., 68 (2019) 231-242. https://doi.org/10.2166/ aqua.2019.067.

[28] Y. Yang, P. Bai, X. Guo, Separation of xylene isomers: a review of recent advances in materials, Ind. Eng. Chem. Res., 56 (2017) 14725-14753. https://doi.org/10.1021/acs. iecr.7b03127.

[29] Z. Vahdat Parast, H. Asilian, A. Jonidi Jafari, Adsorption of xylene from air by Natural Iranian zeolite, Health. Scope, 3 (2014) e17528. https://dx.doi.org/10.17795/ jhealthscope-17528.

[30] S.T. Lim, J.H. Kim, C.Y. Lee, S. Koo, D. W. Jerng, S. Wongwises, H.S. Ahn, Mesoporous graphene adsorbents for the removal of toluene and xylene at various concentrations and its reusability, Sci. Rep., 9 (2019) 1-12. https://doi.org/10.1038/s41598-019-47100-z.

[31] K.W. Shah, W. Li, A Review on catalytic nanomaterials for volatile organic compounds removal and their applications for healthy buildings, Nanomater. (Basel), 9 (2019) 910. https://doi.org/10.3390/nano9060910.

[32] K. Patil, S. Jeong, H. Lim, H. S. Byun, S. Han, Removal of volatile organic compounds from air using activated carbon impregnated cellulose acetate electro spunmats, Environ. Eng. Res., 24 (2019) 600-607. https://doi. org/10.4491/eer.2018.336.

[33] M. Bagheri Hossein Abadi, H. Shirkhanloo, J. Rakhtshah, Air pollution control: the evaluation of TerphApm@MWCNTs as a novel heterogeneous sorbent for benzene removal from air by solid phase gas extraction, Arab. J. Chem., 13 (2020) 1741-1751. https:// doi.org/10.1016/j.arabjc.2018.01.011.
[34] S. KP Veerapandian, N. De Geyter, J. M. Giraudon, J.-F. Lamonier, R. Morent, the use of zeolites for VOCs abatement by combining non-thermal plasma, adsorption, and/or catalysis: a review, Catalysts, 9 (2019) 98. https://doi.org/10.3390/cata19010098.

[35] H. Shirkhanloo, M. Osanloo, O. Qurbandadras, Nobel method for toluene removal from air based on ionic liquid modified nanographene, Int. J. Occup. Hyg., 6 (2014) 1-5. https://ijoh.tums.ac.ir/index.php/ijoh/article/ view/89

[36] M.R. Rezaei Kahkha, M. Kaykhaii, G. Sargazi, B. Rezaei Kahkha, Determination of nicotine in saliva, urine and wastewater samples using tantalum metal organic framework pipette tip micro-solid phase extraction, Anal. Methods, 11 (2019) 61686175. https://doi.org/10.1039/C9AY01773A.

[37] F. Su, C. Lu, S. Hu, Adsorption of benzene, toluene, ethylbenzene and p-xylene by $\mathrm{NaOCl}$-oxidized carbon nanotubes, Colloids. Surf. A. Physicochem. Eng. Asp., 353 (2010) 83-91. http://dx.doi.org/10.1016/j. colsurfa.2009.10.025.

[38] M. Jafarizaveh, H. Shirkhanloo, F. Golbabaei, A. Tabrizi, K. Azam, M. Ghasemkhani, Nobel method for xylene removal from air on nano activated carbon adsorbent compared to NIOSH approved carbon adsorbent, J. Health Safe. Work, 6 (2016) 23-30. https://jhsw.tums. ac.ir/browse.php?a id $=5374 \&$ sid $=1 \&$ slc lang=en 